\title{
A rare case of clomiphene citrate induced moderate ovarian hyperstimulation syndrome
}

\section{Sheetal K. Barhate*, Ameya Dudhwadkar, Rujul Jhaveri, Deepali Kharat-Kapote, Michelle Fonseca}

Department of Obstetrics \& Gynaecology, Lokmanya Tilak Medical College, Mumbai, Maharashtra, India

Received: 05 December 2015

Revised: 06 December 2015

Accepted: 12 December 2015

\section{*Correspondence:}

Dr. Sheetal Barhate,

E-mail: drsheetal2k3@rediffmail.com

Copyright: (C) the author(s), publisher and licensee Medip Academy. This is an open-access article distributed under the terms of the Creative Commons Attribution Non-Commercial License, which permits unrestricted non-commercial use, distribution, and reproduction in any medium, provided the original work is properly cited.

\begin{abstract}
Clomiphene citrate is an orally active non-steroidal triphenylethylene derivative which is commonly used for ovulation induction. It is considered a safe agent and is rarely associated with ovarian hyperstimulation syndrome. This report describes a case of moderate ovarian hyperstimulation syndrome after ovulation induction with clomiphene without associated pregnancy which was managed conservatively.
\end{abstract}

Keywords: Clomiphene citrate, Ovarian hyperstimulation syndrome, Ovulation induction

\section{INTRODUCTION}

Ovarian hyperstimulation syndrome (OHHS) is the most serious complication of ovulation induction. It is a potentially life-threatening situation 1 . It is most commonly associated with in vitro fertilization techniques mainly with gonadotropins. It is also associated with HCG used for luteal support. Clomiphene though considered to be safe can very rarely be associated with OHHS.

\section{CASE REPORT}

We present a case of a 22 year old female with primary infertility who presented to the outpatient department with abdominal pain, nausea and vomiting since 4 days. She had history of ovulation induction with $100 \mathrm{mg}$ of clomiphene citrate from day 2 to day 7 of the present cycle.

There was no shortness of breath or any bladder or bowel disturbances.
No background of any major medical or surgical illness was noted. On further enquiry, there was history of irregular painless menses every 2-3 months.

On clinical examination, her vitals were stable. The abdomen was tender without any guarding or rigidity. There was suggestion of a cystic mass arising from the left side of the pelvis. Abdominal girth was $73 \mathrm{~cm} \mathrm{\&}$ weight was $75 \mathrm{~kg}$.

On per vaginal examination, the uterus was normal \& the right ovary was palpable. There was suspicion of a left ovarian cyst measuring around $10 \mathrm{~cm}$ with left forniceal tenderness.

Patient was then further investigated which revealed: Haemoglobin of $12.6 \mathrm{gm} \%$, White cell count 8500 per cu $\mathrm{mm}$. Platelets were 240000 . The haematocrit was also within normal limits. The liver and renal function tests were unremarkable

Ultrasonography showed mild ascites. The right ovary was bulky with a volume of $20 \mathrm{cc}$. 
The left ovary was $10 \mathrm{~cm}$ in largest dimension with a volume of $190 \mathrm{cc}$. Multiple large follicles were seen some with hyperechoic contents (An ultrasonography done 1 month back was normal). A diagnosis of ovarian hyperstimulation syndrome was made

The patient was managed conservatively with bed rest, pain killers, anti-emetics \& antacids. There was regular daily monitoring of weight, abdominal girth and for worsening of clinical symptoms. Also blood tests like haematocrit, serum electrolytes \& blood urea nitrogen were performed. The patient got her menses 2 weeks later when there was spontaneous reduction of ovarian volume and ascites. She was subsequently put on low dose oral contraceptive pills.

\section{DISCUSSION}

Anovulation is a major cause of female reproductive dysfunction and can be identified in approximately 18$25 \%$ of couples presenting with infertility. Clomiphene is non-steroidal triphenylethylene derivative which is commonly used for ovulation induction. Common side effects include abnormal vaginal bleeding, breast discomfort, headache, nausea and vomiting. It considered safe and is rarely associated with ovarian hyperstimulation syndrome. ${ }^{1-3}$

Diagnosis of OHHS is usually straightforward with history of ovarian stimulation either by gonadotropins or anti-estrogens followed by typical symptoms of abdominal distention, pain, nausea and vomiting. Differentials that need to be kept in mind are complication of an ovarian cyst (torsion, hemorrhage), pelvic infection, intra-abdominal hemorrhage, ectopic pregnancy and appendicitis. ${ }^{4}$

OHHS is classified as mild when there is abdominal bloating with mild abdominal pain and ovaries measure $<8 \mathrm{~cm}$. Moderate OHHS includes moderate pain ,nausea vomiting, ultrasound evidence of ascites and ovarian size 8 to $12 \mathrm{~cm}$ while the diagnosis of severe OHSS is made when there is clinical evidence of ascites, oliguria, hemoconcentration- hematocrit $>45 \%$, ovarian size $>12$ $\mathrm{cm}$. Whereas critical OHHS is associated with tense ascites, hematocrit $>55 \%$, oliguria/anuria, thromboembolism and acute respiratory distress syndrome. ${ }^{5,6}$

Several factors have been demonstrated to independently increase the risk of developing OHSS such as age < 30 years, polycystic ovaries, high serum estradiol at HCG trigger or rapidly rising serum estradiol, previous episodes of OHSS, large number of small follicles ( 8 to $12 \mathrm{~mm}$ ) seen on ultrasonography during ovarian stimulation, use of HCG as opposed to progesterone, for luteal phase support after IVF, large number of oocytes retrieved $(>20)$, and high anti-mullerian hormone $(>3.36$ $\mathrm{ng} / \mathrm{mL})$. $^{5-7}$
Management is essentially supportive until the condition resolves spontaneously. This often involves a multidisciplinary approach and should follow agreed local protocols. Mild and moderate OHHS can be managed on an outpatient basis. ${ }^{6}$ Analgesia using paracetamol or codeine is appropriate. Non-steroidal antiinflammatory drugs should not be used. Strenuous exercise and sexual intercourse should be avoided for fear of torsion of hyperstimulated ovaries. Antiemetic drugs should be those appropriate for possibility of early pregnancy such prochlorperazine, metachlopromide and cyclizine. Daily monitoring for worsening of symptoms, abdominal girth, weight, fluid intake \& output should be done. $^{6,7}$

In case of severe OHHS, intensive care setting may be required. Careful monitoring of fluid balance is needed. Intravenous (IV) fluids should be used if hydration cannot be maintained orally. A colloid such as albumin is given if, despite intensive IV fluid input, a woman remains fluid-depleted. Electrolytes require careful monitoring as hyponatremia is common. Diuretics should be avoided. Aspiration of ascites or pleural effusion can relieve symptoms. Intense monitoring is needed so that complications such as acute kidney injury, thromboembolism, pericardial effusion and ARDS are diagnosed early and managed appropriately. ${ }^{6-8}$

In this case clomiphene was started without complete evaluation of infertility, anovulation was not confirmed, patient was not advised about follicular monitoring and directly $100 \mathrm{mg}$ instead of minimum $50 \mathrm{mg}$ was started. This shows potentially serious effect of clomiphene if used inappropriately.

\section{CONCLUSION}

Thus to conclude though rare, the risk of ovarian hyperstimulation syndrome should not be underestimated with clomiphene and proper evaluation of infertility should be done to minimize unnecessary ovulation induction and minimum dose of clomiphene should be used if needed with proper follicular monitoring.

Funding: No funding sources

Conflict of interest: None declared

Ethical approval: Not required

\section{REFERENCES}

1. Mitchell SY, Fletcher HM, Williams E. Ovarian hyperstimulation syndrome associated with clomiphene citrate. West Indian Med J. 2001;50(3):227-9.

2. Whelan JG, Vlahos NF. The ovarian hyperstimulation syndrome. Fertil Steril. 2000;73:883-96.

3. Nasseri S, Ledger WL. Clomiphene citrate in the twenty-first century. Hum Fertil (Camb). 2001;4(3):145-51. 
4. Roge P, Emy R. Ovarian hyperstimulation syndrome in medically assisted reproduction. Rev Fr Gynecol Obstet. 1994;89(10):495-501.

5. Budev MM, Arroliga AC, Falcone T. Ovarian hyperstimulation syndrome. Crit Care Med. 2005;33(10 Suppl):S301-6.

6. Mathur R, Evbuomwan I, Jenkins J. Prevention and management of ovarian hyperstimulation syndrome. Current Obstet Gynaecol. 2005;15:132-8.

7. Alina OA, Luca A, Bors A. Principles of diagnosis and management in the ovarian hyperstimulation syndrome. Curr Health Sci J. 2013;39:187-92.
8. Klaus Fiedler, Diego Ezcurra. Predicting and preventing of Ovarian hyperstimulation syndrome(OHHS):the need for individualized not standardized treatment(management). Reprod Biol Endocrinol. 2012;10:32.

Cite this article as: Barhate SK, Dudhwadkar A, Jhaveri R, Kapote DK, Fonseca M. A rare case of clomiphene citrate induced moderate ovarian hyperstimulation syndrome. Int J Reprod Contracept Obstet Gynecol 2016;5:258-60. 